\title{
BRASIL: NOVA CLASSE MÉDIA OU NOVAS FORMAS DE SUPEREXPLORAÇÃO DA CLASSE TRABALHADORA?
}

\author{
BRAZIL: NEW MIDDLE CLASS OR NEW WAYS OF OVEREXPLOITING THE WORKING CLASS?
}

\author{
Mathias Seibel Luce ${ }^{1}$
}

Resumo Com base na categoria da superexploração da força de trabalho, formulada no âmbito da teoria marxista da dependência, apresentamos uma crítica à tese de que o Brasil estaria se tornando 'país de classe média' e sustentamos que um contingente substancial dentre o que vem sendo nomeado de 'nova classe média' consiste, na verdade, de trabalhadores - e suas famílias - vivendo em condições de superexploração. $\mathrm{O}$ texto encontra-se dividido em três seções. Na primeira, questionamos os pressupostos básicos da tese Brasil, país de classe média. Na segunda, expomos os fundamentos da categoria da superexploração e demonstramos seu incremento nas relações de produção do capitalismo brasileiro na década de 2000. Na terceira, demonstramos como o acesso da população trabalhadora ao consumo de bens duráveis no período recente, antes que a ascensão de uma suposta 'nova classe média', configura uma forma renovada de superexploração. Por fim, salientamos os nexos entre as condições de trabalho, saúde e direitos da classe trabalhadora no Brasil e as tendências do capitalismo mundial, questionando o falso dilema neoliberalismo e neodesenvolvimentismo no debate atual e colocando a real disjuntiva do ponto de vista da emancipação da classe trabalhadora em relação ao poder despótico do capital.

Palavras-chave superexploração da força de trabalho; teoria marxista da dependência; situação da classe trabalhadora; modelos de desenvolvimento no Brasil.
Abstract Based on the workforce overexploitation category, formulated in the context of the Marxist Theory of Dependence, we critique the thesis that Brazil is becoming 'a middle class nation' and state that a substantial contingent of what has been named the 'new middle class' is, in fact, one of workers - and their families - living in overexploitation conditions. The article is divided into three sections. In the first, we questioned the basic assumptions of the 'Brazil, a middle class nation' thesis. In the second, we explain the fundamentals of the overexploitation category and show how it increased in Brazilian capitalism production relations in the 2000s. In the third, we showed how the access the working population has had to consume durable goods in recent times, before the ascent to the supposed 'new middle class,' is a renewed type of overexploitation. Finally, we highlight the links between the Brazilian working class' labor conditions, health, and rights and the trends in world capitalism, questioning the false neoliberalism and neodevelopmentalism dilemma in the current debate and putting the real dilemma in terms of the emancipation of the working class against the despotic power of capital.

Keywords overexploitation of labor; Marxist Theory of Dependence; working class status; development models in Brazil. 


\section{Nova classe média?}

Uma afirmação que tem sido repetida à exaustão pela grande mídia, pela propaganda do governo e pelos setores acadêmicos identificados com o discurso oficial é o lugar-comum Brasil, país de classe média. Segundo essa visão, a economia brasileira teria se tornado a de um 'país de classe média', haja vista que no último período $35,7 \%$ da população ascenderam à faixa de renda intermediária na classificação por estratos de A a E, ampliando para 53\% da população (104 milhões) os brasileiros pertencentes à assim chamada 'classe média'. A esta pertencem, dizem os epígonos, todo indivíduo que vive com renda per capita familiar entre $\mathrm{R} \$ 291,00$ e R \$ 1.019,00, o que significa uma renda familiar média entre $\mathrm{R} \$ 1.164,00$ e $\mathrm{R} \$ 4.076,00$, ou entre $\mathrm{R} \$ 1.200,00$ e $\mathrm{R} \$ 5.174,00$, para mencionar o critério de um dos principais ideólogos da suposta ascensão de uma nova classe média:

nova classe média foi o apelido que demos à classe $\mathrm{C}(\ldots)$ Chamar a pessoa de classe C soava depreciativo, pior do que classe A ou B (...) Nova classe média dá o sentido positivo e prospectivo daquele que realizou - e continua a realizar - o sonho de subir na vida (Neri, 2011, p. 18).

Em informe publicitário do governo federal, veiculado em dezembro de 2010,2 se podia ler: “Está nos números. Está no dia a dia dos brasileiros. Estamos vivendo o Brasil de todos. 35,7 milhões de brasileiros subiram de classe social e 27,9 milhões superaram a pobreza". Que ideia o discurso oficial quer transmitir? A de que quase 36 milhões de indivíduos não pertenceriam mais à condição de trabalhadores precarizados. Seriam classe média. Seriam trabalhadores com condições de trabalho e de vida dignas. E seriam também empreendedores. Donos do seu próprio negócio. Graças às políticas econômicas e sociais dos oito anos de governo Lula, continuadas pelo governo Dilma, de $37 \%$ da população do país (66 milhões) a classe média teria ultrapassado a casa dos 50\% (104 milhões). Frente a números como estes, cabe ter presente o que escreveu Marx (1985, p. 271): “toda ciência seria supérflua se a forma de manifestação [a aparência] e a essência das coisas coincidissem imediatamente".

Um primeiro conjunto de questionamentos é necessário para refutar caracterização mistificadora da realidade como a que se tem em tela. Primeiro, tal abordagem coloca em um mesmo estrato indivíduos com rendimento familiar mensal tão dissímile como a variação entre R\$ 1.200 e R \$ 5.174 - uma disparidade de $430 \%$ entre o piso e o teto! Segundo, inclui na denominação de classe média um universo de milhões de famílias cujos rendimentos sequer alcançam o salário mínimo necessário do Departamento Intersindi- 
cal de Estatística e Estudos Socioeconômicos (DIEESE). Terceiro, carece de rigor ao apresentar o atributo potencial de consumo 3 - utilizado para comprovar supostamente a sustentabilidade da ascensão à condição de classe média representada pelo consumo de bens duráveis -, ignorando três elementos determinantes: o endividamento das famílias, o aumento do desgaste da força de trabalho para poder acessar tais valores de uso, o barateamento de vários desses produtos, antes bens suntuários, e que passaram à condição de bens de consumo necessário, alterando o elemento histórico-moral do valor da força de trabalho, embora sem que a remuneração recebida tenha acompanhado o aumento do valor da força de trabalho nesse seu componente. Quarto, nubla o verdadeiro significado de classe social, ao se ater à definição de estratos de renda e potencial de consumo. É o que torna lícita afirmação tão esdrúxula como: “a nova classe média também é a classe dominante, do ponto de vista econômico, pois já concentra 46,6\% do poder de compra dos brasileiros em 2011, superando as classes A e B, estas com 45,6\% do total do poder de compra" (Neri, 2011, p. 29). E procura justificá-la desde o princípio, descartando a análise de classe social a partir do antagonismo capital-trabalho:

os sociólogos podem relaxar, pois não estamos falando de classes sociais (operariado, burguesia, capitalistas etc.), mas de estratos econômicos. Leia-se dinheiro no bolso, que seria, segundo os economistas, a parte mais sensível da anatomia humana (Neri, 2011, p. 29).

Na contramão dessa perspectiva, nosso pressuposto considera que a parte mais sensível da anatomia humana é a condição de ser que trabalha e que, na sociedade regida pela relação-capital, tem a sua corporeidade viva, a sua força de trabalho, submetida ao valor-capital, o qual é trabalho morto, riqueza apropriada sobre a base da exploração do trabalho vivo, que gera o valor, sendo o dinheiro, por sua vez, forma ou expressão monetária do valor.

A seguir, passaremos à exposição da categoria da superexploração da força de trabalho e como esta se verifica no Brasil da última década, através das suas diferentes formas.

\section{A categoria superexploração da força de trabalho}

A categoria da superexploração da força de trabalho foi elaborada por Ruy Mauro Marini para dar conta de explicar o fundamento da dependência como modalidade sui generis do capitalismo. Ela pode ser entendida como uma violação do valor da força de trabalho, seja porque a força de trabalho 
é paga abaixo do seu valor, seja porque é consumida pelo capital além das condições normais, levando ao esgotamento prematuro da força vital do trabalhador (Marini, 2005[1973]; 2000 [1978]; Osorio, 1975; 2009; no prelo). ${ }^{4}$ Na condição de superexploração, o capital se apropria do fundo de consumo e/ou do fundo de vida do trabalhador. A superexploração se pode dar mediante quatro formas ou modalidades: a remuneração da força de trabalho por baixo do seu valor (conversão do fundo de consumo do trabalhador em fundo de acumulação do capital); o prolongamento da jornada implicando o desgaste prematuro da corporeidade físico-psíquica do trabalhador; o aumento da intensidade do trabalho provocando as mesmas consequências, com a apropriação de anos futuros de vida e trabalho do trabalhador; e, finalmente, o aumento do valor da força de trabalho sem ser acompanhado pelo aumento da remuneração. ${ }^{5}$

Na primeira e na última forma, o capital atenta contra o fundo de consumo do trabalhador. Nas duas outras, contra o fundo de vida. Isto remete à questão do valor da força de trabalho e às especificidades do capitalismo dependente, que levaram Marini a pensar na necessidade de uma nova categoria para dar conta de explicá-lo. A grande descoberta de Marx, escreveu Engels no prefácio ao Livro II de $O$ capital, foi demonstrar que não é o trabalho que é vendido como mercadoria, mas a força de trabalho, e como e por que o trabalho constitui valor. Superando a teoria ricardiana, Marx deu a conhecer que, mesmo sendo a força de trabalho paga pelo seu valor, havia exploração (Engels, 1983). Por outro lado, Marx não desconhecia a possibilidade de o capital remunerar a força de trabalho abaixo do seu valor ou de consumi-la além das condições normais: "a utilização de minha força de trabalho e a espoliação dela são duas coisas totalmente diferentes" (Marx, 1983, p. 189). 6 No entanto, essa colocação não ocupou sua atenção de maneira mais detida em $O$ capital, dado o nível de abstração que presidia seu raciocínio ali. O recém-exposto é o que justifica o procedimento de Marini de criar uma nova categoria de análise no âmbito do marxismo: "é o conceito de superexploração justamente o que vem a preencher esse vazio teórico na análise da exploração capitalista"7 (Osorio, 1975, p. 7, tradução nossa). De acordo com Osorio, o desdobramento ulterior da categoria da superexploração desenvolvida por Marini passa pela reflexão em torno do fato de que a força de trabalho possui um valor diário e um valor total 8 e que, no capitalismo dependente, ambos tendem a ser violados, transgredidos, de maneira sistemática, como mecanismo praticado nas economias submetidas ao imperialismo para compensar as transferências de valor que são apropriadas por este último. Examinar como se dão as condições de exploração e superexploração em cada momento histórico passa a ser, portanto, um procedimento teórico possível e necessário para a crítica dessa tendência estrutural que marca as relações de produção em economias dependentes, como é o caso do Brasil. 


\section{Pagamento da força de trabalho abaixo do seu valor}

Na história da sociedade capitalista, o estabelecimento de um valor normal da força de trabalho foi duplamente um desdobramento da lógica interna do capital e dos conflitos entre os antagonistas históricos capital e trabalho. O próprio fato de o capital se confrontar com o trabalho em dois momentos, primeiro como o produtor do valor, depois como consumidor, levou a que a burguesia, a partir de determinada conjuntura histórica, tivessse de reconhecer um certo patamar como o valor normal da jornada de trabalho, com a regulamentação do limite da jornada de trabalho, a legislação sobre salário mínimo e outros elementos dos direitos laborais que passaram a expressar as condições para que os trabalhadores reproduzissem normalmente sua força de trabalho, suas próprias condições de vida e as de sua família. Afinal, o capital passava a requerer que os trabalhadores comparecessem na segunda fase da circulação, no processo de realização do capital (Osorio, no prelo). Ao mesmo tempo, foram necessárias duras lutas (movimento cartista, greves, fundação da Associação Internacional dos Trabalhadores etc.) para que fosse estabelecida uma jornada normal de trabalho e uma remuneração mínima condizente.

Como todas as categorias no marxismo, o valor da força de trabalho é uma categoria histórica e relacional. Se no século XIX uma jornada de 10 horas fora o teto que figurou na legislação limitando a duração da jornada conquistada em 1847 na Inglaterra, em 1919 a recém-criada Organização Internacional do Trabalho (OIT) estabelecia em sua primeira convenção que a jornada normal deveria ser de 48 horas semanais e 8 horas diárias, patamar em torno do qual a jornada normal de trabalho tendeu a se estabilizar ao longo do século XX. Paralelamente, um conjunto de atributos passou a compor a remuneração do trabalhador como contraparte necessária para que a força de trabalho fosse paga pelo seu valor (salário mínimo, férias remuneradas, $13 .{ }^{\circ}$ salário etc.).

No Brasil, um parâmetro para avaliar a remuneração da força de trabalho em condições próximas do seu valor é o salário mínimo necessário (SMN). Calculado a partir de 1970 pelo DIEESE, em séries históricas retroativas a 1940, o SMN toma em consideração não apenas o salário mínimo legal no comparativo com a inflação, mas o salário que deveria expressar a quantia necessária para "cobrir os gastos com moradia, alimentação, educação, saúde, lazer, vestuário, higiene, transporte e previdência social". Ou seja, a quantidade de valores de uso necessária para a força de trabalho se reproduzir em condições normais, chegando assim a "uma estimativa de quanto deveria ser o salário mínimo para atender à determinação constitucional" (DIEESE, 2009).

Para calcular o SMN, o DIEESE produz o levantamento do preço médio dos 13 produtos alimentares que constam do decreto-lei n. 399/1938 e nas quantidades especificadas por este. Após, é calculado o gasto mensal 
agregado de cada um dos produtos. Considerando a unidade familiar típica como composta em média por dois adultos e duas crianças e o consumo de uma criança como o equivalente à metade de um adulto, multiplica-se por três o preço mensal da cesta básica do DIEESE e o resultado é novamente multiplicado, agora pelo peso da inflação na porcentagem que a alimentação representa entre os gastos essenciais de uma família no rol dos demais itens avaliados pelo Índice do Custo de Vida (ICV) e que entram também na cesta de consumo do SMN. Com base nesse resultado, produz-se a série histórica a preços correntes do ano em consideração, buscando traçar a evolução do poder de compra do salário mínimo legal em relação à quantidade e aos tipos de valores de uso reconhecidos como necessários para um trabalhador sustentar a si próprio e a sua família.

Observando a série do SMN na comparação com o salário mínimo legal, verifica-se uma tendência histórica de queda abrindo uma fissura entre o primeiro e o último. Na Tabela 1, tomando 1940 como ano-base, temos o índice do SMN para o período 1940-2007.

Tabela 1

Brasil. Salário mínimo necessário. Série histórica. $1940=100$

\begin{tabular}{|c|c|c|c|c|c|c|c|}
\hline Ano & Número índice & Ano & Número índice & Ano & Número índice & Ano & Número índice \\
\hline 1940 & 100,00 & 1957 & 125,12 & 1974 & 55,58 & 1991 & 30,99 \\
\hline 1941 & 91,15 & 1958 & 108,85 & 1975 & 58,05 & 1992 & 26,59 \\
\hline 1942 & 81,83 & 1959 & 121,85 & 1976 & 57,67 & 1993 & 29,96 \\
\hline 1943 & 73,98 & 1960 & 102,32 & 1977 & 60,10 & 1994 & 25,29 \\
\hline 1944 & 84,86 & 1961 & 113,77 & 1978 & 61,92 & 1995 & 25,02 \\
\hline 1945 & 68,38 & 1962 & 103,87 & 1979 & 62,52 & 1996 & 25,42 \\
\hline 1946 & 60,00 & 1963 & 91,31 & 1980 & 63,02 & 1997 & 25,82 \\
\hline 1947 & 45,84 & 1964 & 94,35 & 1981 & 64,62 & 1998 & 27,08 \\
\hline 1948 & 47,82 & 1965 & 90,98 & 1982 & 67,35 & 1999 & 27,19 \\
\hline 1949 & 43,03 & 1966 & 77,56 & 1983 & 57,23 & 2000 & 27,96 \\
\hline 1950 & 40,64 & 1967 & 73,37 & 1984 & 53,08 & 2001 & 30,27 \\
\hline 1951 & 37,53 & 1968 & 71,80 & 1985 & 54,31 & 2002 & 30,88 \\
\hline 1952 & 100,76 & 1969 & 69,16 & 1986 & 51,37 & 2003 & 31,32 \\
\hline 1953 & 82,99 & 1970 & 70,32 & 1987 & 37,03 & 2004 & 32,49 \\
\hline 1954 & 100,87 & 1971 & 67,29 & 1988 & 38,99 & 2005 & 34,99 \\
\hline 1955 & 113,28 & 1972 & 66,09 & 1989 & 41,52 & 2006 & 40,44 \\
\hline 1956 & 115,08 & 1973 & 60,56 & 1990 & 29,67 & 2007 & 42,59 \\
\hline
\end{tabular}

Nota: ano-base $=1940$

Fonte: Calculado em números índice a partir de Cepal, PNUD e OIT (2008), com dados de DIEESE. 
Os anos 1957 a 1959 correspondem ao período de pico do SMN, quando este esteve cerca de $20 \%$ acima do poder de compra original e representando quatro vezes o poder de compra que assumiria o salário legal praticado em 2002.9 Em 201 1, o salário mínimo corrente apresentava menos da metade do poder de compra na comparação com o ano de sua criação. Essa análise colide com a aparência de que haveria ocorrido recorde no aumento do salário mínimo real, como afirma o discurso oficial. Isto ocorre porque, para a teoria hegemônica, salário real significa poder de compra do salário nominal (o resultado da divisão do salário nominal pelo índice geral de preços). $\mathrm{Na}$ Tabela 2, temos o reajuste do salário mínimo oficial praticado nos anos 2003-2010.

Tabela 2

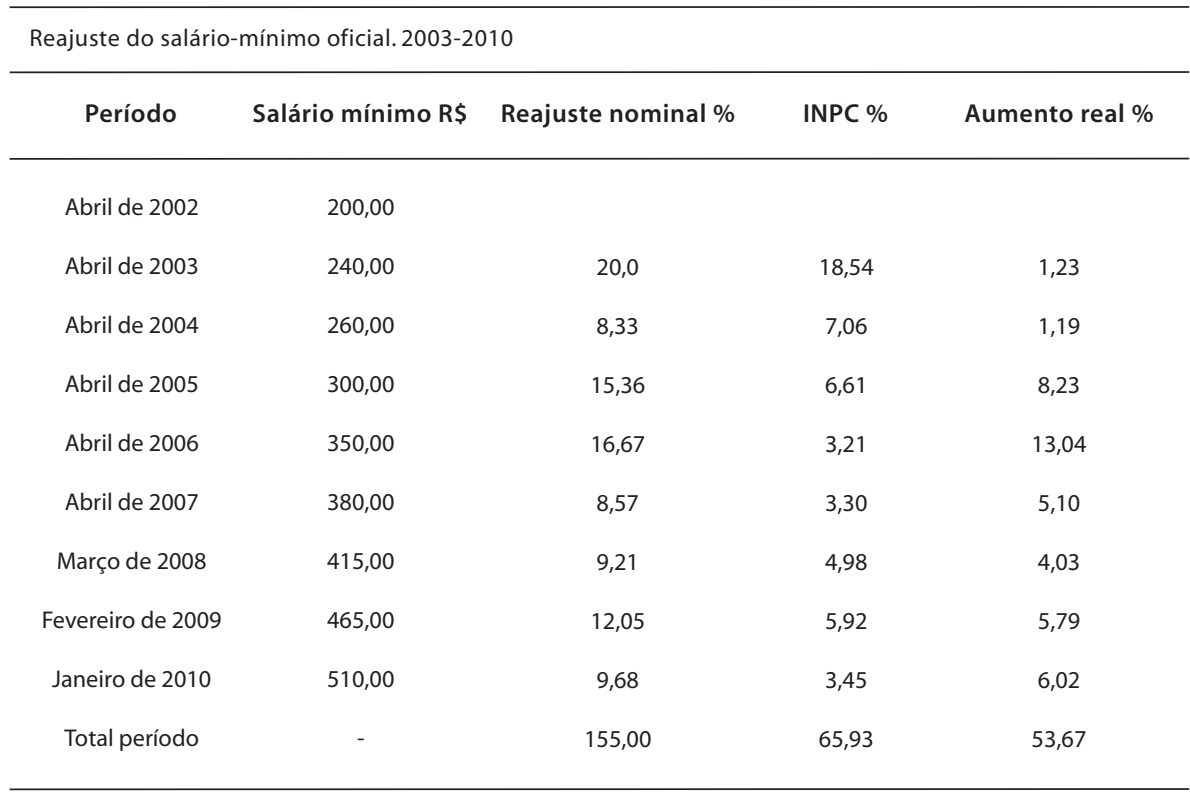

Fonte: DIEESE $(2010$, p. 3).

Ainda que reconheçamos que o poder de compra do salário mínimo real no sentido hegemônico (o salário nominal mais reajustes em relação à inflação do período) tenha apresentado melhora relativa nos anos Lula e Dilma na comparação com os anos 1990, a discussão não pode restringir-se ao terreno superficial da comparação salário mínimo oficial e inflação. Se formos mais a fundo e entendermos, conforme a teoria marxista da dependência (TMD), que salário real significa a relação do salário com o valor da força de trabalho, veremos como o propalado aumento recorde do salário mínimo esteve longe de recuperar 
as perdas anteriores, como se vê ao confrontarmos os índices do reajuste do salário mínimo legal com a série histórica do salário mínimo do DIEESE (salário mínimo necessário). Ainda é raro encontrarmos análises que desvelem esse fundamento. 10

Hoje em torno de $\mathrm{R} \$ 2.617,00$ (outubro de 2012), o SMN equivale a mais de quatro vezes o salário mínimo vigente de $\mathrm{R} \$ 622,00.11$ Se o salário não alcança a quantia suficiente para o trabalhador repor o desgaste de sua força de trabalho, estaremos diante da superexploração. Isto significa que a força de trabalho está sendo remunerada abaixo do seu valor. Uma objeção que poderia ser feita à afirmação anterior é que o salário mínimo praticado tomaria como referência a remuneração mínima para um adulto da família se sustentar e que hoje tanto o homem como a mulher trabalham em troca de salário, ao passo que à época da implementação da legislação do salário mínimo (década de 1940) - que o DIEESE utiliza como parâmetro para o SMN - o mais típico era que apenas o homem exercesse trabalho assalariado. Ora, tal afirmação, antes que depor contra o argumento por nós utilizado, reforça-o. O fato de hoje, em muitas famílias da classe trabalhadora brasileira, nem o salário do marido e da esposa somados alcançarem o patamar considerado como remuneração normal evidencia o quanto a tendência observada expressa uma violação do valor da força de trabalho.

Segundo dados da Pesquisa Nacional por Amostra de Domicílio (PNAD), de 2011, do total dos trabalhadores brasileiros ocupados, 23,6\% recebem até 1 salário mínimo; $22,4 \%$, de 1 a 2 salários mínimos; e 9,0\%, de 2 a 3 salários mínimos. Somando essas três faixas de rendimento do trabalho, constata-se que $55 \%$ da população trabalhadora recebe até 3 salários mínimos. ${ }^{12}$ Considerando que o salário mínimo fixado para o ano de 2011 foi de R \$ 545,00 e que o SMN em dezembro de 2011 equivalia a $\mathrm{R} \$ 2.329,00$ a preços de então, mais da metade dos trabalhadores brasileiros recebiam remuneração entre 4,27 e 1,42 vezes abaixo do SMN. Estipulando como média dos dois primeiros segmentos mencionados a remuneração de 1 salário mínimo e meio, $45 \%$ receberam salário 2,85 vezes inferior ao SMN. Esse é um dado mais fidedigno que o simples cálculo do rendimento médio mensal do conjunto das pessoas ocupadas, que tende a encobrir os baixos níveis de remuneração ao incluir na estatística a composição com os salários mais elevados.

Se cruzarmos esses dados com o da geração de empregos formais na década de 2000 no país, dos quais $95 \%$ são de até 1 salário mínimo e meio (Pochmann, 2012, p. 19), isto é, até $\mathrm{R} \$ 933,00$ a preços correntes, veremos que tanto o reajuste do salário mínimo como a criação de empregos com carteira assinada não apontam no sentido de uma alteração das precárias condições de vida e trabalho.

A seguir, examinaremos como, mesmo que a força de trabalho fosse paga pelo seu valor, existem mecanismos que permitem ao capital apropriar-se do 
fundo de vida do trabalhador, tornando ainda mais complexa e necessária a tarefa da crítica radical e das lutas pela emancipação do trabalho do poder despótico do capital.

\section{Prolongamento da jornada de trabalho}

Entre 2003 e 2009, em média 40\% dos trabalhadores brasileiros cumpriram jornadas semanais acima de $44 \mathrm{~h}$, isto é, superiores à jornada normal de trabalho. Nas regiões metropolitanas, 25,5\% tiveram jornadas semanais de $49 \mathrm{~h}$ ou mais (Luce, 2012). Se o limiar da jornada normal de trabalho está sendo ultrapassado, é porque estamos diante de condições de superexploração mediante prolongamento da jornada de trabalho, implicando que o capital se aproprie de anos de vida futuros do trabalhador. Na Tabela 3, temos os dados dos assalariados que trabalharam acima da jornada legal por setor da economia, na Região Metropolitana de São Paulo.

Tabela 3

Assalariados que trabalham mais do que a jornada legal (1) por setor da economia. Região Metropolitana de São Paulo (\%)

\begin{tabular}{llll}
\hline Ano & Indústria & Comércio & Serviços (2) \\
\hline 1990 & 34,8 & 49,9 & 32,2 \\
1991 & 38,3 & 53,6 & 33,5 \\
1992 & 36,7 & 53,0 & 34,3 \\
1993 & 38,7 & 55,3 & 32,6 \\
1994 & 39,8 & 54,4 & 33,2 \\
1995 & 42,5 & 55,2 & 35,8 \\
1996 & 41,4 & 55,2 & 36,8 \\
1997 & 42,2 & 56,0 & 37,3 \\
1998 & 37,9 & 57,5 & 36,5 \\
1999 & 40,7 & 59,1 & 38,2 \\
2000 & 44,4 & 61,1 & 39,5 \\
2001 & 43,4 & 59,2 & 38,2 \\
2002 & 44,1 & 62,2 & 38,8 \\
2003 & 43,2 & 60,6 & 39,2 \\
2004 & 42,4 & 59,1 & 38,0 \\
2005 & 38,8 & 56,6 & 36,5 \\
2006 & 36,7 & 55,0 & 35,2 \\
\hline
\end{tabular}

Nota: (1) A partir de novembro de 1988, a jornada legal passou de 48 para 44 horas. (2) Exclui serviços domésticos. Fonte: Marques, Capelas e Huertas Neto (2010, p. 223), com dados de Pesquisa de Emprego e Desemprego (PED) 
Em todos os setores, na comparação 1990-2006, se elevou o percentual de trabalhadores que têm de se submeter a jornadas superiores à jornada legal. A leve queda observada após os anos de pico na duração da jornada - os quais registraram $44,4 \mathrm{~h}$ para a indústria, em 2000; 60,6h para o comércio, em 2003; 39,2h para os serviços, em 2003 - não fez com que fosse recuperado o patamar das jornadas existentes em 1990. E no comércio e nos serviços houve elevação de $12 \%$ e 10\%, respectivamente, entre 1990 e 2006 , sendo que no comércio chegou a estar $20 \%$ mais elevada no ano de pico da série histórica considerada (o ano de 2003). A realidade pode ser de jornadas inclusive ainda mais extensas. As estatísticas a respeito da duração da jornada de trabalho registram a jornada do trabalhador em sua ocupação principal. Mas, segundo a PNAD 2008 (apud Prieb, 2011), 4,2 milhões de trabalhadores declararam precisar exercer dois ou mais empregos para sobreviver, número que tende a ser maior, considerando os não-declarados.

Que implicações tem o fato de que em ramos como comércio cerca de $60 \%$ dos trabalhadores trabalham além do limite da jornada normal semanal? E que no setor de serviços, onde se concentrou a geração de empregos formais na última década, 38\% cumprem jornadas acima da duração normal? O prolongamento da jornada de trabalho por anos reiterados, mediante o uso sistemático de horas extras, atinge um momento que, mesmo com o pagamento de remuneração adicional pelas horas trabalhadas além da jornada normal, uma maior quantia de valores de uso não bastará para repor o desgaste de sua corporeidade viva. O capital estará se apropriando do fundo de vida do trabalhador (Osorio, 1975; 2009; no prelo).

Como expressão superestrutural da superexploração nas duas formas vistas até aqui, podemos mencionar algumas medidas adotadas pelo Estado sancionando a violação do valor da força de trabalho: (1) banco de horas; 13 (2) abertura do comércio aos domingos; (3) flexibilização da CLT autorizando a venda de 1/3 das férias; (4) flexibilização da CLT, mediante portaria do Ministério do Trabalho e Emprego (MTE), facultando negociar redução de $50 \%$ do horário de almoço.

Nos termos da portaria de 20 de maio de 2010, do MTE, publicada ao final do segundo mandato do governo Lula, fica permitida a redução pela metade do horário de almoço dos trabalhadores, de $1 \mathrm{~h}$, estabelecido pela CLT, quando houver acordo entre sindicato e entidade patronal. Tal medida é uma a mais dentre as que vêm se perfilando no sentido de uma flexibilização das condições de trabalho para proveito do capital, como fora o decreto-lei n. 1535, de 1977, que liberou a venda de 1/3 das férias, e tantas outras levadas a cabo nos anos 1990 e 2000. Do ponto de vista do capital, reduzir os poros da jornada - seja a jornada diária, seja a jornada anual - de modo a exigir do trabalhador maior dispêndio de sua força viva sem incorrer em custos adicionais para contratação de novos empregados consiste de um 
método de se apropriar de uma massa superior de valor atentando contra o fundo de vida do trabalhador. Quanto a este, contar com menos tempo para repouso e recuperação de sua força vital - seja reduzindo o tempo de almoço, seja reduzindo o tempo de descanso semanal, seja ainda reduzindo o tempo de descanso de férias - não poderá ser compensado com aumento da quantidade de bens consumidos. Com isso, o sobredesgaste de sua corporeidade físico-psíquica tende a levar à piora de suas condições de vida, ao adoecimento e ao esgotamento prematuro de seu tempo de vida útil. Que os trabalhadores aceitem essas medidas em troca de adicionais/abonos salariais apenas revela como a remuneração da força de trabalho por baixo de seu valor leva a que tenham de se submeter à violação de seu fundo de vida no esforço de tentar compensar a apropriação de seu fundo de consumo. Aqui vemos, flagrantemente, se combinarem duas formas de superexploração, a conversão do fundo de consumo do trabalhador em fundo de acumulação do capital e o prolongamento da jornada além da jornada normal, ambos atentando, isto é, violando, respectivamente, o fundo de consumo e o fundo de vida do trabalhador.

\section{Aumento da intensidade do trabalho}

Assim como no prolongamento da jornada além do limite normal, o trabalho a ritmos/intensidade mais elevados leva ao esgotamento prematuro da corporeidade viva do trabalhador. Todos devem ter em mente o personagem Carlitos, de Chaplin, que de tanto apertar parafusos em movimentos repetitivos a ritmos extenuantes adoeceu física e psiquicamente. O aumento da intensidade ou o dispêndio de atos de trabalho sob intensidade elevada se pode dar de diversas maneiras, dependendo de cada trabalho concreto útil. Um metalúrgico na linha de montagem executará trabalho mais intenso conforme aumente a velocidade da esteira que regula o ritmo da produção ou conforme a velocidade dos movimentos desse trabalhador nas estações de trabalho. Um controlador de tráfego aéreo estará trabalhando sob alta intensidade em sentido diretamente proporcional ao tempo em que não deverá tirar os olhos do painel de controle, de preferência sem piscá-los, e dispondo de raros intervalos ou pausas. Um carteiro com elevada intensidade de trabalho carregará em sua bolsa funcional um sobrepeso - e é costume entre os trabalhadores dessa categoria adivinhar os anos de serviço de seus colegas conforme apresentem problemas no joelho ou tenham se submetido a cirurgia para implantação de pino nas articulações ou no ombro.

Conforme argumentou Marini, “a exigência de mais-trabalho ao operário, mediante procedimentos extensivos ou intensivos, ao provocar fadiga e 
esgotamento, resulta no incremento do que Marx chamou 'as pestes de guerra do exército industrial"', que têm nos acidentes de trabalho um de seus indicadores mais representativos (Marini, 2000, p. 229). A maior ocorrência de acidentes de trabalho e doenças laborais é um indicador que aponta a tendência a uma superexploração. Mas como distinguir o que corresponde a um aumento do desgaste devido ao prolongamento da jornada e aquele que é devido ao incremento da intensidade ou ritmo do trabalho? E como desvelar o que acontece no âmbito da intensidade, diferenciando-a da produtividade, questão que costuma ser completamente ignorada dentro da ideologia crescimentista? "Trata-se, de fato, de fenômeno difícil de ser captado a nível de dados globais" (Marini, 2000, p. 227).

Enquanto o aumento da produtividade implica que o trabalho executado pelo trabalhador transforme maior quantidade de meios de produção no mesmo tempo, no aumento da intensidade há extração de mais-trabalho pelo capital mediante elevação do ritmo ou desgaste físico no mesmo tempo. E sempre que tal intensidade for elevada acima das condições normais, se estará superexplorando o trabalhador.

No Brasil, verificamos diferentes circunstâncias de aumento da intensidade provocando o aumento do desgaste da força de trabalho. Em uma das primeiras pesquisas a utilizar o referencial teórico formulado por Marini, Nilson Araújo de Souza, em estudo da luta de classes no ciclo de expansão acelerada chamado apologeticamente pelos ideológos da ditadura militar de "Milagre", identificou a ocorrência de superexploração mediante aumento da intensidade na indústria automobilística, encontrando nela a chave para explicar como a produção de automóveis dobrara sem que houvesse sido alterada a composição técnica do capital, permanecendo igual a produtividade naquele ramo industrial nos anos observados. Um caso de superexploração mediante aumento da intensidade em sua expressão mais nítida (Souza, 1980).

$\mathrm{O}$ aumento da intensidade pode - e costuma - se dar também combinadamente com o aumento dos níveis de produtividade. Assim como no anterior padrão de reprodução do capital,14 a indústria automobilística é um dos ramos de maior dinamismo no novo padrão exportador de especialização produtiva, tendo alcançado 19\% do PIB industrial em 2009 e levado o Brasil à quarta posição na produção mundial de automóveis. Conforme dados da Associação Nacional dos Fabricantes de Veículos Automotores (Anfavea), entidade patronal do setor automotivo, em 2007 cada trabalhador produzia mais que o dobro de veículos em relação a 1994. Se no discurso do capital esse dado é apresentado simplesmente como ganho de produtividade, sob a perspectiva da TMD precisa passar pelo crivo da crítica metodológica.

Pensemos no caso da fábrica da General Motors (GM) de São José dos Campos. Em 1997, com o capital produtivo de 12.000 trabalhadores, eram 
produzidos 37 carros a cada hora. Em 2005, empregando 2.000 trabalhadores a menos, a mesma fábrica ampliava sua produção para 74 veículos por hora trabalhada. Como saber o quanto desse aumento da produção por hora trabalhada se deve a maior produtividade e a maior intensidade? Mesmo sem dispormos dos indicadores para medir a alteração nos meios de produção e na organização técnica desta unidade fabril, o fato de 6.000 operários da GM no Brasil terem passado por afastamento por doenças laborais apenas no ano de 2008 - o que representa $30 \%$ da força de trabalho da empresa - já é por si só uma comprovação irrefutável de que a superexploração do trabalho mediante aumento da intensidade cobra grande importância nessa indústria (Luce, 2012).15

Prossigamos nossa análise, com outro ramo da produção à frente do atual padrão de reprodução do capital: o setor sucroalcooleiro, segmento que obtém sua matéria-prima com base no trabalho degradante dos cortadores manuais da cana-de-açúcar que trabalham em condições alarmantes. Segundo estudo com os cortadores manuais em atividade no interior paulista, em apenas dez minutos cada trabalhador corta $400 \mathrm{~kg}$ de cana, desfere 131 golpes de facão e flexiona o tronco 138 vezes. Ao final de um dia de trabalho, após numerosas sequências de operações repetitivas e extenuantes, são computados em média por trabalhador: 11,5 toneladas de cana cortada, 3.792 golpes de facão e 3.994 flexões de coluna. Como resultado, tem-se expectativas de vida que não passam dos 35 anos de idade (Laat, 2008).

Esse dado brutal é a realidade nua e crua do capital se apropriando do fundo de vida do trabalhador, superexplorando-o mediante tamanho grau de intensidade que leva à exaustão completa e à morte. Resistindo novamente à aparência dos fenômenos, é necessário colocar que, antes que solucionar o problema do trabalho em condições sub-humanas, o estímulo à mecanização do corte da cana - defendida como solução pelo governo - sem que se altere a lógica das relações de produção exercerá, e está já exercendo, pressão para que os trabalhadores de empresas não-mecanizadas sejam obrigados a cumprir cotas ainda maiores de produção, fazendo elevar ainda mais o esgotamento de sua força de trabalho. Esse caso evidencia como a superexploração por aumento da intensidade cumpre um papel para as empresas com menor produtividade que estão perdendo uma parcela de mais-valia via mercado, a qual é apropriada pelas empresas operando acima da taxa de lucro média.

Finalmente, um quarto caso que não será tratado neste artigo, mas que cabe mencionar, é do aumento da intensidade em ramos com jornadas menores ou part-time, como telemarketing. O trabalhador, mesmo com meia jornada, pode estar sendo superexplorado a ritmos/níveis de intensidade que levam ao seu esgotamento prematuro - e não é por nada que são as empresas desse ramo que concentram uma parcela importante de doenças físicas e psíquicas. 
A ocorrência de acidentes de trabalho e de doenças laborais continua a ser o principal indicador para auferir o aumento da intensidade. De acordo com dados do Instituto Nacional do Seguro Social (INSS), do Ministério da Previdência Social, no Brasil quase dobraram os acidentes de trabalho entre 2002 e 2008, passando de 393.071 a 747.663, como se vê na Tabela 4.

Tabela 4

\begin{tabular}{cccccc}
\hline Número total de acidentes de trabalho no Brasil & & \\
\hline Período & Típico com CAT & Trajeto com CAT & $\begin{array}{c}\text { Doença de trabalho } \\
\text { Com CAT }\end{array}$ & Sem CAT & Total \\
\hline 1997 & 347.482 & 37.213 & 36.648 & 0 & 421.343 \\
1998 & 347.738 & 36.114 & 30.489 & 0 & 414.341 \\
1999 & 326.404 & 37.513 & 23.903 & 0 & 387.820 \\
2000 & 304.963 & 39.300 & 19.605 & 0 & 363.868 \\
2001 & 282.965 & 38.799 & 18.487 & 0 & 340.251 \\
2002 & 323.879 & 46.881 & 22.311 & 0 & 393.071 \\
2003 & 325.577 & 49.642 & 23.858 & 0 & 399.077 \\
2004 & 375.171 & 60.335 & 30.194 & 0 & 465.700 \\
2005 & 398.613 & 67.971 & 33.096 & 0 & 499.680 \\
2006 & 407.426 & 74.636 & 30.170 & 0 & 512.232 \\
2007 & 417.036 & 79.005 & 22.374 & 18.51 .108 & 659.523 \\
2008 & 438.536 & 88.156 & 309.711 & 202.395 & 747.663 \\
Total & 4.295 .790 & 655.565 & 343.503 & 5.604 .589 \\
\hline
\end{tabular}

Nota: CAT (Comunicação de Acidente de Trabalho).

Fonte: Bordignon (2009); com dados de NetUNO, http://www.inss.gov.br.

Para os órgãos do governo, essa elevação de $40 \%$ poderia ser devida à mudança na metodologia - que passou a incluir as aposentadorias por invalidez - e ao aumento da apuração de casos de doenças ocupacionais, através de registros CAT16 (INSS, 2009). Entretanto, a mudança metodológica e a maior fiscalização não explicam todo o incremento dos registros. Como procuramos demonstrar, o incremento de ritmos extenuantes e de doenças laborais em ramos específicos da economia - dois dos ramos da produção de maior importância no modelo de desenvolvimento adotado no Brasil em nossos dias (indústria automobolística e setor sucroalcooleiro) e em um dos ramos que mais vem crescendo no setor que concentrou a geração de empregos formais na última década (serviços) - confirma que os números da escalada de acidentes de trabalho e doenças laborais (LER/DORT etc.) expressam a tendência atual do capitalismo brasileiro de elevar o desgaste da corporeidade físico-psíquica do trabalhador. 


\section{O aumento do elemento histórico-moral do valor da força de trabalho sem aumentar a remuneração}

Por fim, cabe considerar uma última modalidade em que a superexploração pode ter lugar que é o aumento do elemento histórico-moral do valor da força de trabalho sem aumentar a remuneração recebida. No capitalismo dependente, o avanço das forças produtivas mediante nova composição técnica do capital não tende a gerar concessões à classe trabalhadora da mesma maneira como ocorreu no capitalismo dominante. E menos ainda comparativamente ao que foram os anos áureos deste último. A despeito disso, as transformações da sociedade foram colocando novas necessidades, que fizeram aumentar a quantidade de bens necessários na cesta de consumo dos trabalhadores: "o desenvolvimento material da sociedade e a generalização de novos bens vão transformando estes [novos bens] em bens necessários em épocas determinadas" (Osorio, 2009, p. 179). A isto Marx chamou de elemento histórico-moral do valor da força de trabalho. É o que explica que

não há nada de estranho no fato de que, nas periferias urbanas pobres, multipliquem-se as antenas de televisão apesar de seus habitantes não contarem com alimentos básicos. O que deve surpreender não são as antenas, mas que, nesse grau de desenvolvimento social, existam pessoas que não possam contar com os bens materiais básicos, próprios da época em que vivem, e satisfazer ao mesmo tempo e de maneira suficiente o resto de suas necessidades (Osorio, 2009, p. 179).

Produtos que antes eram francamente suntuários, isto é, bens de consumo de luxo, com o tempo passaram à condição de bens de consumo corrente ou bens-salário, ou seja, bens de consumo necessário que fazem parte da cesta de consumo dos trabalhadores. Dois exemplos notórios, o televisor e a máquina de lavar, que eram bens suntuários nas décadas de 1960 e 1970 hoje são valores de uso encontrados inclusive nos lares de famílias que vivem em moradias precárias e com renda familiar abaixo do necessário. Tais valores de uso deixaram a condição de bens de luxo tanto porque o avanço da fronteira tecnológica barateou a sua produção como porque passaram a expressar necessidades que a sociabilidade capitalista colocou para os trabalhadores.

Se um televisor passa a ser necessário na sociabilidade que vai sendo criada com o capitalismo17 e se uma lavadora automática passa a ser a maneira de facilitar as atividades domésticas que cumprem um papel para a reprodução da força de trabalho (em um contexto de aumento do seu desgaste e de aumento do tempo de deslocamento até o local de trabalho), esses são valores de uso que passam a compor o elemento histórico-moral do valor da força de trabalho. 
Mas e se a única forma de o trabalhador acessar tais bens de consumo que se tornaram bens necessários for endividar-se ou submeter-se a uma carga extra de trabalho? Estaremos diante de uma alteração do elemento histórico-moral sem ser acompanhada pela remuneração. Ou seja, aumento do valor da força de trabalho sem aumentar o seu pagamento. Ao ter de elevar o desgaste de sua força de trabalho (cumprir mais horas-extras, vender $1 / 3$ das férias etc.) e ao ter de endividar-se para acessar tais valores de uso, os indivíduos da família trabalhadora estarão ou se submetendo a uma violação de seu fundo de vida para compensar parcialmente a insuficiência de seu fundo de consumo ou comprometendo o seu próprio fundo de consumo futuro, mediante endividamento, na tentativa de compensar a sua violação no presente.

O que o discurso governista e dos acadêmicos alinhados com o oficialismo não querem revelar é que o aumento comemorado do consumo de eletromésticos por parte da chamada classe $C$, que seria supostamente a 'nova classe média', se deu em grande medida com base no endividamento das famílias. É o que se observa na Tabela 5, na página seguinte.

Desagregando o consumo total de eletrodomésticos por estratos de renda, nas estatísticas da PNAD de 2002 a 2010, verifica-se que enquanto a participação dos estratos D e E manteve-se estacionada e a faixa de rendimentos A e B apresentou queda relativa de $18,05 \%$, o aumento expressivo na compra de eletrodomésticos se deu no estrato de renda C, que respondia por 26,61 em 2002 e passou a representar $45 \%$ das compras de produtos eletroeletrônicos na apuração de 2010.

De fato, foi a faixa de renda $\mathrm{C}$ - que insistimos, e não é por nada, em não chamar de uma classe à parte - a responsável pelo aumento das vendas de eletrodomésticos. Agora, cabe desvendar a outra face oculta. Considerando que a maior parte das compras desses produtos é feita a prazo e que, segundo levantamento da Confederação Nacional dos Dirigentes Logistas (CNDL), $64 \%$ das famílias inadimplentes (o somatório da classificação de $\mathrm{Cl}$ até $\mathrm{E}$ da publicação da CNDL) recebem entre R\$ 600 e $\mathrm{R} \$ 2.200$ - quer dizer, abaixo do salário mínimo necessário - cerca de 2/3 das famílias inadimplentes possuem remuneração abaixo do valor da força de trabalho. Se tomarmos em consideração o estrato B2 da pesquisa da CNDL, que compõe também o estrato $\mathrm{C}$ da classificação utilizada pelo IBGE e pelo governo, esse percentual será ainda maior.

Do recém exposto pode-se concluir que, sem que estivesse endividada, uma parcela significativa das famílias consideradas 'classe $C^{\prime}$ não teria conseguido tornar-se consumidora de tais produtos, mesmo que sua produção tenha barateado e mesmo que tenham se tornado bens necessários, como um refrigerador ou uma máquina de lavar. Se esses produtos, sob a própria lógica do capital, tivessem se tornado bens de consumo necessário, atuariam no sentido de reduzir o valor da força de trabalho, permitindo que os 
Consumo de eletrodomésticos e endividamento das famílias por estratos de renda (\%)

Participação dos estratos de renda (1) no consumo de eletrodomésticos

$\begin{array}{cccc}\text { Ano } & \text { A e B } & \text { C } & \text { D e E } \\ 2002 & 55,16 & 26,61 & 18,23 \\ 2010 & 37,11 & 44,67 & 18,22\end{array}$

Estratos de renda e situação financeira familiar no cadastro de devedores (2)

Estratos de renda

Até $R \$ 600,00(E)$

De R\$ 601 a R\$ 905 (D)

De $R \$ 906$ a R\$ 1.375 (C2)

De $R \$ 1.337$ a $R \$ 2.200$ (C1)

De $R \$ 2.201$ a $R \$ 3.285$ (B2)

De $R \$ 3.286$ a $R \$ 7000(B 1)$

De R\$ 7.001 a $\mathrm{R} \$ 11.100(\mathrm{~A} 2)$

Mas de R\$ 11.000 (A1)

\section{Adimplente}

$4 \%$

$15 \%$

$19 \%$

$20 \%$

$26 \%$

$12 \%$

$3 \%$

$2 \%$
Inadimplente

$2 \%$

$15 \%$

$19 \%$

$28 \%$

$22 \%$

$11 \%$

$1 \%$

$1 \%$

\% famílias inadimplentes que recebem abaixo do salário mínimo necessário

$64 \%(3)$

Nota: (1) A: mais de 20 salários mínimos; B: de 10 a 20 salários mínimos; C: de 3 a 10 salários mínimos; D: de 1 a 3 salários mínimos; E: menos de 1 salário mínimo. (2) Classificação da Confederação Nacional dos Dirigentes Logistas (CNDL) (3) sem considerar famílias da porção inferior do estrato B2 na classificação da CNDL, que integram a faixa de renda C da PNAD, o que faz o percentual ser ainda maior.

Fonte: elaboração própria, com dados do Instituto Brasileiro de Geografia e Estatística (IBGE), PNAD (2002 a 2010) e CNDL/UFMG (2012).

trabalhadores os consumissem ao mesmo tempo em que o dispêndio de capital para a contratação da força de trabalho se visse reduzido mediante a ampliação da mais-valia relativa e não mediante superexploração. Mas se é somente à custa da redução do fundo de consumo do trabalhador (consumir menos alimento para ter um televisor ou uma lavadora) e de seu fundo de vida (trabalhar redobrado, além da duração normal e da intensidade normal da jornada) que o trabalhador consegue acessar tais bens que se tornaram necessários, isso significa que do ponto de vista da relação-capital tais valores de uso não passaram a integrar o valor da força de trabalho. Assim, configura-se, na verdade, uma quarta forma de superexploração, o hiato entre o elemento histórico-moral do valor da força de trabalho e o pagamento desta. Esta quarta modalidade da superexploração pode ser entendida como uma forma desdobrada da primeira que discutimos neste artigo - o pagamento da força de trabalho abaixo do seu valor. Porém, seu tratamento analítico 
específico se justifica, pois ela apresenta a particularidade de violação do valor da força de trabalho quando esta se dá em relação ao componente histórico e moral do valor da força de trabalho que se viu alterado, mas atuando no sentido contrário ao da mais-valia relativa. 18

\section{Conclusão}

Do exposto até aqui, pode-se extrair algumas conclusões a respeito do incremento da superexploração no Brasil da última década, nos anos Lula e Dilma, e que são ao mesmo tempo observações que demonstram a vigência da categoria da superexploração da força de trabalho, apontando alguns dos indicadores para seu estudo. A superexploração pode ocorrer seja em atividades como a dos cortadores manuais de cana, como na indústria automobilística, não sendo sinônimo da persistência de formas antediluvianas do capital. A superexploração pode ocorrer inclusive no caso de trabalhadores que recebam remuneração acima do salário mínimo necessário, mediante a prolongação da jornada e da intensidade além do limite normal. A superexploração também pode ter lugar entre trabalhadores que cumpram jornadas de meio turno, como no telemarketing. O exame das relações de produção no Brasil na última década revela que o fato mais determinante é a persistência de longas jornadas e o seu incremento em alguns setores, assim como o incremento dos níveis de intensidade do trabalho, ao mesmo tempo em que os níveis salariais praticados contrastam com o discurso oficial de que se estaria fazendo a "maior distribuição de renda na história do país". Na contramão da ideologia dominante e do discurso acadêmico hegemônico, esperamos ter contribuído para demonstrar que, longe da visão mistificadora e idílica da ascensão de uma nova classe média, estamos diante de formas renovadas de superexploração da classe trabalhadora.

A chamada 'classe $\mathrm{C}^{\prime}$, que seria a 'classe majoritária', só é majoritária em termos percentuais porque é classe trabalhadora e não 'classe média', termo que remete - mesmo que seus ideológos o neguem - à ideia de estrato intermediário entre proprietários do capital e trabalhadores comuns. Que os indivíduos na faixa de renda intermediária tenham se tornado consumidores de bens duráveis como eletrodomésticos não é indicador de que tenham deixado a condição de trabalhadores precarizados. Os dados demonstram que o grosso da 'classe $\mathrm{C}^{\prime}$ consiste de trabalhadores que cumprem longas jornadas, muitas vezes com ritmos extenuantes, que recebem abaixo do salário mínimo necessário, muitos deles sendo pessoas jurídicas (PJs), mas que atuam como trabalhadores terceirizados e sem direitos laborais. São trabalhadores que precisam, enfim, recorrer ao endividamento para acessar os valores de uso que deveriam fazer parte do elemento histórico-moral de sua 
força de trabalho, mas que não estão a seu alcance em condições normais devido a esta forma renovada de superexploração que se combina às demais.

Essas conclusões ajudam a recolocar criticamente o debate sobre o suposto antagonismo entre neoliberalismo e neodesenvolvimentismo como ideologias e como políticas econômicas na presente quadra histórica. O que temos assistido nos últimos anos é o neodesenvolvimentismo aprofundar a flexibilização dos direitos trabalhistas e permitir o incremento da superexploração da força de trabalho, vendendo ilusões de que o Brasil estaria se encaminhando para superar as mazelas de sua população trabalhadora. Na atual conjuntura mundial de crise estrutural do capital (Mészáros, 2009), somente com a crítica aguda e o debate rigoroso entre acadêmicos, sindicatos, movimentos sociais e formuladores de políticas alternativas e uma práxis consequente é que se poderá apresentar um modelo de desenvolvimento alternativo, que esteja vinculado às lutas pela superação do capital como forma histórica da reprodução social.

\section{Notas}

1 Professor do Departamento de História da Universidade Federal do Rio Grande do Sul (UFRGS), Porto Alegre, Rio Grande do Sul, Brasil, e Coordenador do Núcleo de História Econômica da Dependência Latino Americana (HEDLA). Doutor em História pela Universidade Federal do Rio Grande do Sul (UFRGS). <mathias.seibel@ufrgs.br>

Correspondência: Universidade Federal do Rio Grande do Sul, Instituto de Filosofia e Ciências Humanas Departamento de História, Avenida Bento Gonçalves, 9.500, prédio 43.311, CEP 91509-900, Bairro Agronomia, Porto Alegre, Rio Grande do Sul, Brasil.

2 Ver, por exemplo, Carta Capital, ano XVI, n. 625, edição de 8 de dezembro de 2010.

3 Para uma definição marxista do significado de classes sociais e a crítica ao uso de estratos categoria de análise, ver Mészáros (2008, Cap. 2; 2004, Cap.7) e Osorio (2001, Cap. VI).

4 Na superexploração, "a característica essencial está dada pelo fato de que são negadas ao trabalhador as condições necessárias para repor o desgaste de sua força de trabalho (...) seja porque se obriga o trabalhador a um dispêndio de força de trabalho superior ao que deveria proporcionar normalmente, provocando assim seu esgotamento prematuro; (...) [seja] porque se lhe retira inclusive a possibilidade de consumir o estritamente indispensável para conservar sua força de trabalho em estado normal" (Marini, 2005 [1973], p. 156-157).

5 Para uma discussão da categoria superexploração da força de trabalho, ver também Amaral e Carcanholo (2012) e Martins (1999).

6 No original, em alemão: "Die Benutzung meiner Arbeitskraft und die Beraubung derselben sind ganz verschiedne Dinge". A passagem em que Marx utiliza um diálogo hipotético entre 
um trabalhador e o capital para expor que a força de trabalho pode ser paga abaixo do seu valor e consumida além das condições normais encontra-se no capítulo sobre a jornada de trabalho no Volume I de $O$ capital. Essa formulação é uma das fontes para a ideia da superexploração da força de trabalho em Marini e Jaime Osorio, a qual, contudo, possui estatuto teórico próprio, como categoria específica da TMD, que teve em Marini seu fundador e principal expoente e que encontra nas análises de Osorio um de seus principais continuadores. Ver Osorio (2009; 2012, cap. 2, p. 50-52).

7 No original: "Es el concepto de superexplotación justamente el que viene llenar este vacío teórico en el análisis de la explotación capitalista".

8 “Na análise feita por Marx sobre o valor da força de trabalho, encontram-se presentes duas dimensões: de um lado, o valor diário, de outro, o valor total. Este último considera o tempo total de vida útil do trabalhador ou o total de dias que o possuidor da força de trabalho pode vender a sua mercadoria no mercado em boas condições, além dos anos de vida em que não participará na produção (ou os anos de aposentadoria) (...) o valor diário da força de trabalho deve ser calculado considerando um determinado tempo de vida útil dos trabalhadores e de vida média total, de acordo com as condições existentes na época. Os avanços na medicina social, por exemplo, permitiram elevar a expectativa de vida, razão por que o tempo de vida produtiva e o de vida total também se prolongaram. Isso implica que, se atualmente um indivíduo pode trabalhar por trinta anos sob condições normais, o pagamento diário da força de trabalho deve permitir a ele se reproduzir de tal forma que possa apresentar-se no mercado de trabalho durante trinta anos e viver por um determinado número de anos de aposentadoria em condições normais, e não menos. (...) O valor diário da força de trabalho é determinado pelo valor dos meios de vida necessários para assegurar a subsistência e a reprodução do seu possuidor. Aparecem aqui as necessidades referidas de alimentação, vestuário, moradia, educação, saúde, etc." (Osorio, 2009, p.176-177).

${ }_{9}$ A este respeito, ver também Souza (2008, p. 36).

10 Entre os diversos grupos de estudos sobre a TMD existentes hoje no Brasil, Niemeyer Almeida Filho e Marisa Silva Amaral, do Instituto de Economia da Universidade Federal de Uberlândia (IE-UFU), estão desenvolvendo pesquisa sobre o salário mínimo necessário no Brasil. No HEDLA, está se desenvolvendo pesquisa sobre a evolução do valor da força de trabalho em países latino-americanos selecionados.

11 Ver a respeito em <http://www.dieese.org.br/rel/rac/salminMenu09-05.xml>.

12 Ver a respeito em <ftp://ftp.ibge.gov.br/Trabalho_e_Rendimento/Pesquisa_ Nacional_por_Amostra_de_Domicilios_anual/2011/tabelas_pdf/sintese_ind_7_1_1.pdf>.

13 Algumas considerações sobre o banco de horas foram feitas em nosso artigo já citado. Ver Luce (2012).

14 Para uma definição da categoria padrão de reprodução do capital, ver Osorio (2012).

15 A fonte dos dados é o Sindicato dos Metalúrgicos de São José dos Campos.

16 “A CAT (Comunicação de Acidente de Trabalho) é um instrumento do INSS, que deve ser preenchido e registrado toda vez que ocorrer um acidente de trabalho ou uma suspeita de doença ocupacional. A empresa é a responsável pelo seu preenchimento, mas caso se recuse, a CAT pode ser preenchida pelo próprio trabalhador, pelo sindicato, por um 
médico ou por uma autoridade de saúde, desde que haja um médico que ateste o problema. Caberá ao INSS validá-la ou não" (Bernardo, 2009, p. 156).

17 Ver comentário de Jaime Osorio a esse respeito no debate realizado na mesa-redonda "A categoria superexploração da força de trabalho". Vídeo disponível em: <www.ufrgs.br/hedla/videos>.

18 “O aumento do número de bens necessários que o desenvolvimento histórico propicia pressiona no sentido da elevação do valor da força de trabalho. Mas, em geral, o aumento da produtividade e o barateamento dos bens indispensáveis atuam em sentido contrário, de modo que o valor da força de trabalho se veja permanentemente pressionado por essas duas forças" (Osorio, 2009, p. 179).

\section{Referências}

AMARAL, Marisa; CARCANHOLO, Marcelo Dias. Superexploração da força de trabalho e transferência de valor: fundamentos da reprodução do capitalismo dependente. In: FERREIRA, Carla; OSORIO, Jaime; LUCE, Mathias Seibel (Orgs.). Padrão de reprodução do capital: contribuições da Teoria Marxista da Dependência. São Paulo, Boitempo Editorial, 2012.

BERNARDO, Maria Hespanhol. Trabalho duro, discurso flexível: uma análise das contradições do toyotismo a partir da vivência dos trabalhadores. São Paulo: Expressão Popular, 2009.

BORDIGNON, Liseane. Estudo de caso: o trabalhador e o acidente de trabalho. Porto Alegre, Faculdade de Medicina - Universidade Federal do Rio Grande do Sul (UFRGS), 2009. Disponível em: $<$ http://www.lume.ufrgs.br>. Acesso em: setembro 2012.

CEPAL/PNUD/OIT (Comissão Econômica para a América Latina e o Caribe, Programa das Nações Unidas para o Desenvolvimento, Organização Internacional do Trabalho). Déficit de trabalho decente no Brasil. Emprego, desenvolvimento humano e trabalho decente: a experiência brasileira recente. Brasília, DF: CEPAL/PNUD/OIT, 2008. Dispo- nível em: <www.pnud.org.br/publicacoes/ emprego/Cap2.pdf> . Acesso em: outubro 2012.

CNDL/UFMG (Confederação Nacional dos Dirigentes Logistas, Universidade Federal de Minas Gerais). Pesquisa perfil do consumidor com e sem dívidas no Brasil. Out. 2012. Disponível em: <www.cndl.org.br/mostra capa.php?.id=470>. Acesso em: outubro 2012.

DIEESE (Departamento Intersindical de Estatística e Estudos Socioeconômicos). Política de valorização do salário-mínimo. Nota Técnica, n. 86, jan. 2010. Disponível em <www. dieese.org.br>. Acesso em: outubro 2012.

Salário mínimo: instrumento de combate à desigualdade. São Paulo: DIEESE, 2009.

ENGELS, Friedrich. Prefácio. In: MARX, Karl. O capital. Crítica da economia política. Volume II. São Paulo: Abril Cultural, 1983.

IBGE/PNAD (Instituto Brasileiro de Geografia e Estatística/Pesquisa Nacional por Amostra de Domicílio). 2002 a 2011. Disponível em $<$ www.ibge.gov.br>. Acesso em: outubro 2012.

INSS (Instituto Nacional do Seguro Social). Anuário Estatístico sobre Acidentes de 
Trabalho. 2009. Disponível em <www. previdenciasocial.gov.br/conteudoDinamico. php?id=423> . Acesso em: nov. 2012.

LAAT, Erivelton Fonta de. Trabalho e risco no corte manual de cana-de-açúcar: a maratona perigosa nos canaviais. Comunicação apresentada no seminário Condições de Traballho no Plantio e Corte de Cana. Campinas, Procuradoria Regional do Trabalho da $15^{\text {a }}$ Região, 24 e 25 de abril de 2008.

LUCE, Mathias Seibel. A superexploração da força de trabalho no Brasil. Revista da Sociedade Brasileira de Economia Politica, São Paulo, n. 32, p. 119-141, junho 2012.

MARINI, Ruy Mauro. Dialética da dependência. Tradução de Marcelo Dias Carcanholo. In: STÉDILE, João Pedro; TRASPADINI, Roberta (Orgs.). Ruy Mauro Marini: vida e obra. São Paulo: Expressão Popular, 2005.

. As razões do neodesenvolvimentismo. In: SADER, Emir (Org.). Dialética da dependência. Antologia de Ruy Mauro Marini. Petrópolis: Vozes, 2000.

MARQUES, Rosa; CAPELAS, Estela; HUERTAS NETO, Miguel. Relações de trabalho e flexibilização. In: MARQUES, Rosa; FERREIRA, Mariana Ribeiro Jansen (Orgs.). $O$ Brasil sob a nova ordem: a economia brasileira contemporânea. Uma análise dos governos Collor a Lula. São Paulo: Saraiva, 2010.

MARTINS, Carlos Eduardo. Superexploração do trabalho e acumulação de capital: reflexões teórico-metodológicas para uma economia política da dependência. Revista da Sociedade Brasileira de Economia Politica, Rio de Janeiro, n. 5, p. 121-38, dez. 1999.

MARX, Karl. O capital. Crítica da economia política. São Paulo: Nova Cultural, 1983. v. 1.

O capital. Crítica da economia política. São Paulo: Nova Cultural, 1985. v. III, t. II.

MÉSZÁROS, István. A crise estrutural do capital. São Paulo: Boitempo Editorial, 2009.
. Filosofia, ideologia e ciência social.

São Paulo: Boitempo Editorial, 2008.

O poder da ideologia. São Paulo:

Boitempo Editorial, 2004.

NERI, Marcelo. A nova classe média. São Paulo: Saraiva, 2011.

OSORIO, Jaime. Fundamentos da superexploração. In: ALMEIDA FILHO, Niemeyer (Org.). Superexploração e desenvolvimento dependente. No prelo.

. Padrão de reprodução do capital: uma proposta teórica. In: FERREIRA, Carla; OSORIO, Jaime; LUCE, Mathias Seibel (Orgs.). Padrão de reprodução do capital: contribuições da Teoria Marxista da Dependência. São Paulo: Boitempo Editorial, 2012.

Dependência e superexploração. In: MARTINS, Carlos Eduardo; SOTELO VALENCIA, Adrián (Orgs.). A América Latina e os desafios da globalização: ensaios dedicados a Ruy Mauro Marini. São Paulo: Boitempo Editorial, 2009.

Fundamentos del análisis social: La realidad social y su conocimiento. Cidade do México, Fondo de Cultura Económica, 2001.

Superexplotación y clase obrera. El caso mexicano. Cuadernos Políticos, Cidade do México, Era, n. 6, p. 5-23, 1975.

POCHMANN, Márcio. Nova classe média? O trabalho na base da pirâmide social brasileira. São Paulo: Boitempo Editorial, 2012.

PRIEB, Sérgio. As novas configurações do trabalho diante da crise. Novos Temas, São Paulo, v. 2, n. 2, set.-mar. 2010/2011, p. 53-63.

SOUZA, Nilson Araújo de. Crisis y lucha de clases en Brasil. 1974/1979. México, Facultad Nacional de Economía - UNAM, 1980. Tese de Doutoramento. Orientador, Ruy Mauro Marini. 